\title{
Coupling moisture diffusion and internal mechanical states in polymers - A thermodynamical approach
}

\author{
B.E. Sar ${ }^{a}$, S. Fréour ${ }^{a}$, P. Davies ${ }^{b}$, F. Jacquemin ${ }^{a, *}$ \\ a Institut de Recherche en Génie Civil et Mécanique, UMR CNRS 6183, LUNAM Université, Université de Nantes, \\ Ecole Centrale de Nantes, 37 Bd de I'Université, BP 406, 44602 Saint-Nazaire, France \\ ${ }^{b}$ Service Matériaux et Structures, IFREMER, Centre de Brest, B.P. 70, 29280 Plouzané, France \\ *: Corresponding author : Frédéric Jacquemin, email address : frederic.Jacquemin@univ-nantes.fr
}

\begin{abstract}
:
A thermodynamical approach, based on the definition of the chemical potential of water, is used in order to establish a model coupling the diffusion of moisture to the mechanical behaviour of a polymer. The model takes into account the evolution, occurring during the diffusion process, of both the density of the polymer and its maximum moisture absorption capacity. The approach developed is applied to symmetric loading cases, in terms of relative humidity and external pressure. The model, established in the present work, provides the water content profiles through the thickness of the polymer throughout the transient phase of the diffusion process. The numerical results obtained show the significant effect of an external pressure on the kinetics of moisture diffusion in polymers.
\end{abstract}

\section{Highlights}

A model coupling the diffusion of moisture to the mechanical states is proposed. The model is based on a thermodynamical approach. - The model takes into account the evolution of the density of the polymer. An external pressure has a significant effect on the kinetics of moisture diffusion.

Keywords: Hygromechanical coupling ; Moisture absorption ; Thermodynamical approach

\section{Introduction}

Fiber reinforced organic matrix composites are being increasingly used for aircraft, marine and civil engineering structural applications. Such composite structures are often subjected to humid environments during their service life (Jedidi et al., 2005). Organic matrix composites do absorb significant amount of water when exposed to moisture. Many authors have reported that hygro-thermal ageing could induce a loss of the mechanical stiffness and/or strength of organic matrix composites (Patel et al., 2002). Moreover, the constituents of composite structures exhibit heterogeneous coefficients of moisture expansion (CME) and maximum moisture absorption capacity. As a consequence, multi-scale mechanical behaviour profiles arise during the hygroscopic loading of organic matrix composites. According to the literature, the resulting mechanical states can eventually induce damage 
(Perreux and Suri, 1997; Weitsman and Elahi, 2000). Therefore, considerable research efforts have been made in order to develop analytical models to predict the multi-scale mechanical states occurring during both the transient stage and the permanent regime of the moisture diffusion process in organic matrix composites subjected to hygro-mechanical loads (Jacquemin and Vautrin, 2002; Fréour et al., 2005). In this field of research, the most recent investigations (Aboudi and Williams, 2000; Derrien and Gilormini, 2009; Youssef et al., 2009, 2011) focus upon taking into account, in the theoretical approaches, various features of hygro-mechanical coupling, observed during experimental studies, and in particular the dependence of both the moisture diffusion coefficient and the maximum moisture absorption capacity on the mechanical states (strains and stresses) (Marom and Broutman, 1981; Neumann and Marom, 1986, 1987). These models aim eventually to enable the prediction of the long-term durability of composite structures subjected to hygroscopic loads.

The purpose of this study is to establish a model coupling the diffusion of moisture to the mechanical states by a thermodynamical approach, based on the expression satisfied by the 
chemical potential of water. Moreover, the present study aims to consider additional factors that have not yet been taken into account in the pioneering works of Derrien and Gilormini(Derrien and Gilormini, 2009), such as the evolution of the polymer density as a function of the mechanical states, which occurs in practice during the moisture diffusion process.

\section{CONSERVATION OF MASS EQUATION}

The uncoupled law of Fick is classically used for modeling the diffusion of moisture in organic matrix composites. The adjective "uncoupled" refers to the fact that the model disregards any effect due to the mechanical states on the moisture diffusion process. However, the experimental investigation reported in (Gilat and Broutman, 1978)shows that an anomalous sorption process (i.e. it deviates from the classical Fickianbehaviour) takes place in practice. According to (Weitsman, 1990), the anomalies could be explained by coupled constitutive equations, based on the principles of continuum mechanics and irreversible thermodynamics.

In practice, the coupled method relates the flux of moisture to the chemical potential $\tilde{\mu}_{w}$ :

$\mathrm{J}_{\mathrm{i}}=-\frac{\mathrm{DC}}{\mathrm{RT}} \nabla \tilde{\mu}_{w}$

Where $\mathrm{D}$ is the diffusion coefficient in $\left[\mathrm{mm}^{2} / \mathrm{s}\right], \mathrm{C}$ is the moisture content in [\%], $\mathrm{R}$ is the ideal gas constant in $[\mathrm{kJ} /(\mathrm{mol} . \mathrm{K})], \mathrm{T}$ is the temperature in $[\mathrm{K}]$.

The coupled diffusion equation which expresses the law of mass conservation is given by (Larché and Cahn, 1982):

$\frac{\partial \mathrm{C}}{\partial \mathrm{t}}+\mathrm{J}_{\mathrm{i}, \mathrm{i}}=0$

\section{CHEMICAL POTENTIAL}

The chemical potential of water $\tilde{\mu}_{w}$ is defined as the partial derivative of free energy of Helmholtz, $\mathrm{F}=\mathrm{F}_{0}+\mathrm{nf}_{\mathrm{w}}(\mathrm{C})+\mathrm{V}_{\varepsilon} \mathrm{W}$, with respect to the amount of water $\mathrm{n}_{\mathrm{w}}$. Where $\mathrm{F}_{0}$ is the free energy of the dry stress-free polymer, $\mathrm{f}_{\mathrm{w}}(\mathrm{C})$ is the variation of the free energy per mole of dry polymer, due to the addition of water when the polymer is free to swell, $\mathrm{n}$ andV $\mathrm{V}_{\varepsilon}$ are respectively the amount of polymer and its volume at any stage, whereas $\mathrm{W}$ denotes the hygroelastic strain energy (Derrien and Gilormini, 2009):

$\tilde{\mu}_{w}(\mathrm{C})=\frac{\partial \mathrm{F}}{\partial \mathrm{n}_{\mathrm{w}}}=\frac{\partial \mathrm{F}}{\partial \mathrm{C}} \frac{\partial \mathrm{C}}{\partial \mathrm{n}_{\mathrm{w}}}$

The moisture content in the polymer is calculated throughC $=\frac{\mathrm{n}_{\mathrm{w}} \omega_{\mathrm{w}}}{\mathrm{n} \omega}$, where $\omega_{\mathrm{w}}$, $\omega$ stand for respectively the molar mass of water and polymer.

The hygro-elastic strain energy written as a function of both the bulk modulus $\mathrm{k}$ and shear modulus $\mathrm{G}$, is defined by:

$\mathrm{W}=\frac{1}{2} \boldsymbol{\sigma}: \boldsymbol{\varepsilon}^{\mathrm{el}}=\frac{\mathrm{k}}{2}(\operatorname{tr} \boldsymbol{\varepsilon}-3 \eta \mathrm{C})^{2}+\mathrm{Ge}: \mathbf{e}$

Where $\varepsilon^{\mathrm{el}}$ is the elastic strain, $\varepsilon$ being the total strain, $\mathbf{e}$ the deviatoric strain tensor. $\eta$ denotes the coefficient of moisture expansion of the polymer. 
Introducing $\mathrm{f}_{\mathrm{W}}^{\prime}(\mathrm{C})=\frac{\partial\left[\mathrm{f}_{\mathrm{w}}(\mathrm{C})\right]}{\partial \mathrm{C}}$, one obtains the following expression for the derivative of the Helmholtz free energy with respect to the moisture content:

$\frac{\partial \mathrm{F}}{\partial \mathrm{C}}=\frac{\partial \mathrm{F}_{0}}{\partial \mathrm{C}}+\mathrm{nf}_{\mathrm{W}}^{\prime}(\mathrm{C})+\mathrm{V}_{\varepsilon} \frac{\partial \mathrm{W}}{\partial \mathrm{C}}+\mathrm{W} \frac{\partial \mathrm{V}_{\varepsilon}}{\partial \mathrm{C}}$

Let us assume that

i). following the historical hypotheses accounted in (Derrien and Gilormini, 2009), the derivative of polymer volume with respect to moisture content is considered as negligible, i.e. $\frac{\partial \mathrm{V}_{\varepsilon}}{\partial \mathrm{C}}=0$,

ii). the bulk modulus $\mathrm{k}$, and the shear modulus $\mathrm{G}$, do not depend on the moisture content $\left(\frac{\partial \mathrm{k}}{\partial \mathrm{C}}=\frac{\partial \mathrm{G}}{\partial \mathrm{C}}=0\right)$ and

iii). the derivative of the strain tensor trace by the moisture content is also negligible: $\frac{\partial}{\partial \mathrm{C}}(\operatorname{tr} \varepsilon)=0$.

Accounting for above the approximations i) to iii) in $(8,10)$ yields

$\frac{\partial \mathrm{F}}{\partial \mathrm{C}}=\mathrm{nf}_{\mathrm{w}}^{\prime}(\mathrm{C})+\mathrm{V}_{\varepsilon} \frac{\partial}{\partial \mathrm{C}}\left[\frac{\mathrm{k}(\mathrm{C})}{2}(\operatorname{tr} \varepsilon-3 \eta \mathrm{C})^{2}+\mathrm{Ge}: \mathbf{e}\right]=\mathrm{nf}_{\mathrm{w}}^{\prime}(\mathrm{C})+\mathrm{V}_{\varepsilon} \mathrm{k}(\operatorname{tr} \varepsilon-3 \eta \mathrm{C})(-3 \eta)$

The chemical potential can finally be written as,

$\tilde{\mu}_{w}(\mathrm{C})=\frac{\omega_{\mathrm{w}}}{\omega} \mathrm{f}_{\mathrm{w}}^{\prime}(\mathrm{C})+\mathrm{k}(\operatorname{tr} \varepsilon-3 \eta \mathrm{C})(-3 \eta) \frac{\omega_{\mathrm{w}}}{\rho_{\varepsilon}}$

Where $\frac{\omega_{\mathrm{w}}}{\omega} \mathrm{f}_{\mathrm{w}}^{\prime}(\mathrm{C})=\mu_{0}+\mathrm{RT} \ln \frac{\mathrm{C}}{\mathrm{C}_{0}} \cdot \mu_{0}$ denotes the chemical potential of water in the strain-free polymer, whereas the reference moisture content is given by $\mathrm{C}_{0}$.

During the moisture diffusion process, we take into account the evolution of the volume occupied by the polymer, and the resulting variation of its density, through

$\frac{\mathrm{V}_{\varepsilon}}{\mathrm{V}_{0}}=\frac{\rho_{0}}{\rho_{\varepsilon}}=\operatorname{tr} \varepsilon+1$

Where $V_{\varepsilon}, V_{0}, \rho_{\varepsilon}, \rho_{0}$ stand respectively for the polymer volume and its density at present and initial states.

Assuming the mechanical properties of the polymer to be independent of both the mechanical states and the moisture content, the chemical potential can be written as,

$\tilde{\mu}_{w}(\mathrm{C}, \operatorname{tr} \varepsilon)=\mu_{0}+\mathrm{RT} \ln \frac{\mathrm{C}}{\mathrm{C}_{0}}-\frac{3 \eta \omega_{\mathrm{w}} \mathrm{k}}{\rho_{0}}(\operatorname{tr} \varepsilon-3 \eta \mathrm{C})(\operatorname{tr} \varepsilon+1)$

\section{HYGROSCOPIC PRESSURE}

The hygro-elastic Hooke's law is:

$\varepsilon_{i j}=\frac{1+v}{E} \sigma_{i j}-\frac{v}{E}\left(\operatorname{tr} \sigma_{i j}\right) \delta_{i j}+\eta C \delta_{i j}$ 
Where $v$ stands for Poisson's ratio, E for Young's modulus, and $\delta_{i j}=\left\{\begin{array}{l}1 \text { ifi }=j \\ 0 \text { ifi } \neq j\end{array}\right.$.

The Beltrami-Michell equation leads to:

$(1+v) \sigma_{\mathrm{ij}, \mathrm{kk}}+\sigma_{\mathrm{kk}, \mathrm{ij}}+\mathrm{E \eta}\left(\frac{1+v}{1-v} \delta_{\mathrm{ij}} \mathrm{C}_{, \mathrm{kk}}+\mathrm{C}_{, \mathrm{ij}}\right)=0$

Furthermore, introducing the Laplacian operator $\Delta$, one can write:

$\Delta\left(\operatorname{tr} \sigma_{i j}+2 \eta \frac{E}{1-v} C\right)=0$

In the present case, a hydrostatic external pressure Pex is assumed to be applied at the boundary of a cubic element, so that the total pressure is $\mathrm{P}=\mathrm{Pex}+\mathrm{Pis}$ where the hygroscopic pressure to be determined is denoted by Pis. As a result, $\operatorname{tr} \sigma_{i j}=-3 \mathrm{P}$. Besides, $\Delta \mathrm{Pex}=0$.

As a consequence, the hygroscopic pressure depends on the moisture content through:

$\Delta \mathrm{Pis}=\frac{\alpha}{\mathrm{A}_{0}} \eta \Delta \mathrm{C}$

Where,

$\frac{\alpha}{A_{0}}=\frac{2 E}{3(1-v)}$

$\mathrm{A}_{0}=\frac{3 \omega_{\mathrm{w}}}{\mathrm{RT} \rho_{0}}$

\section{EQUATION OF MODEL}

The constitutive equation is obtained by using the mass conservation equation (2) in which the chemical potential of water has been written as a function of the trace of the strains and the moisture content:

$\frac{\partial \mathrm{C}}{\partial \mathrm{t}}=\frac{\mathrm{D}}{\mathrm{RT}} \operatorname{div}\left[\mathrm{C}\left(\overrightarrow{\operatorname{grad}} \tilde{\mu}_{w}(\mathrm{C}, \operatorname{tr} \boldsymbol{\varepsilon})\right)\right]$

Since

$\overrightarrow{\operatorname{grad}} \tilde{\mu}_{w}(\mathrm{C}, \operatorname{tr} \varepsilon)=\frac{\partial \widetilde{\mu}_{w}}{\partial \mathrm{C}} \overrightarrow{\operatorname{grad}} \mathrm{C}+\frac{\partial \widetilde{\mu}_{w}}{\partial \operatorname{tr} \epsilon} \overrightarrow{\operatorname{grad}} \operatorname{tr} \varepsilon$

$\frac{\partial \widetilde{\mu}_{w}}{\partial \mathrm{C}}=\frac{\mathrm{RT}}{\mathrm{C}}+\frac{9 \eta^{2} \mathrm{k} \omega_{\mathrm{w}}}{\rho_{0}}(\operatorname{tr} \boldsymbol{\varepsilon}+1)$

$\frac{\partial \widetilde{\mu}_{w}}{\partial \operatorname{tr} \varepsilon}=-\frac{3 \mathrm{k} \omega_{w} \eta}{\rho_{0}}(2 \operatorname{tr} \varepsilon-3 \eta C+1)$

Therefore the equation (16) could be written as follow, 
$\frac{\partial C}{\partial t}=\operatorname{Ddiv}\left[\overrightarrow{\operatorname{grad}} C+\frac{9 \eta^{2} \mathrm{k} \omega_{\mathrm{w}}}{\mathrm{RT} \rho_{0}} \mathrm{C}(\operatorname{tr} \varepsilon+1) \overrightarrow{\operatorname{grad}} \mathrm{C}-\frac{3 \mathrm{k} \omega_{\mathrm{w}} \eta}{\mathrm{RT} \rho_{0}}(2 \operatorname{tr} \varepsilon-3 \eta C+1) C \overrightarrow{\operatorname{grad}} \operatorname{tr} \varepsilon\right]$

This implies,

$\frac{\partial \mathrm{C}}{\partial \mathrm{t}}=\mathrm{D}\left[\Delta \mathrm{C}+\frac{9 \eta^{2} \mathrm{k} \omega_{\mathrm{w}}}{\mathrm{RT} \rho_{0}} \mathrm{C}(\operatorname{tr} \varepsilon+1) \Delta \mathrm{C}+\frac{9 \eta^{2} \mathrm{k} \omega_{\mathrm{w}}}{\mathrm{RT} \rho_{0}} \overrightarrow{\operatorname{grad}}[\mathrm{C}(\operatorname{tr} \varepsilon+1)] \overrightarrow{\operatorname{grad}} \mathrm{C}-\frac{3 \mathrm{k} \omega_{\mathrm{w}} \eta}{\mathrm{RT} \rho_{0}}(2 \operatorname{tr} \varepsilon-3 \eta \mathrm{C}+\right.$ 1) $\left.\mathrm{C} \Delta \operatorname{tr} \varepsilon-\frac{3 \mathrm{k} \omega_{\mathrm{w}} \eta}{\mathrm{RT} \rho_{0}} \overrightarrow{\operatorname{grad}}[(2 \operatorname{tr} \varepsilon-3 \eta \mathrm{C}+1) \mathrm{C}] \overrightarrow{\operatorname{grad}} \operatorname{tr} \varepsilon\right]$

Since the trace of the strain in term of the pressure load is given by,

$\operatorname{tr} \varepsilon=-\frac{3(\mathrm{Pex}+\mathrm{Pis})}{3 \mathrm{k}}+3 \eta \mathrm{C}$

This implies the gradient of strain trace can be written as follows,

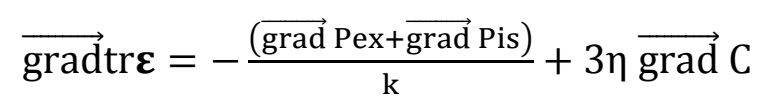

Knowing that the gradient of external pressure is given by,

$\overrightarrow{\operatorname{grad}} \operatorname{Pex}=0$

\section{TOWARDS AN EXPLICIT SOLUTION: THE CASE OF AN UNIDIRECTIONAL MOISTURE DIFFUSION}

In order to find an explicit solution to relation (21), an unidirectional moisture diffusion is assumed to occur along $\mathrm{x}$ axis. As a result, the solution of equation (13) satisfies,

$\operatorname{Pis}(\mathrm{x}, \mathrm{t})=\frac{\alpha}{\mathrm{A}_{0}} \eta C(\mathrm{x}, \mathrm{t})+\mathrm{k}_{1}(\mathrm{t}) \mathrm{x}+\mathrm{k}_{2}(\mathrm{t})$

The constants $k_{1}(t)$ and $k_{2}(t)$ are deduced from the equilibrium conditions in which $L$ is the dimension along the $\mathrm{x}$ axis,

$\int_{0}^{\mathrm{L}} \operatorname{Pis}(\mathrm{x}, \mathrm{t}) \mathrm{dx}=0$

$\int_{0}^{L} \operatorname{Pis}(x, t) x d x=0$

The final form of equation (13) is given by:

$\operatorname{Pis}(\mathrm{x}, \mathrm{t})=\frac{\alpha}{\mathrm{A}_{0}} \eta(\mathrm{C}(\mathrm{x}, \mathrm{t})-\overline{\mathrm{C}(\mathrm{t})})$

Where

$\overline{C(t)}=\frac{1}{L} \int_{0}^{L} C(x, t) d x$

As a result, the gradient of the hygroscopic pressure is given by, 
$\overrightarrow{\operatorname{grad}} \operatorname{Pis}=\frac{\partial}{\partial \mathrm{x}}\left(\frac{\alpha}{\mathrm{A}_{0}} \eta(\mathrm{C}(\mathrm{x}, \mathrm{t})-\overline{\mathrm{C}(\mathrm{t})})\right)=\frac{\alpha}{\mathrm{A}_{0}} \eta \frac{\partial \mathrm{C}}{\partial \mathrm{x}}$

It should be noted that $\overline{\mathrm{C}(\mathrm{t})}$ only depends on the time (i.e., it is independent of the position), thus its derivative with respect to the position is obviously zero: $\frac{\partial \overline{\mathrm{C}(\mathrm{t})}}{\partial \mathrm{x}}=0$.

So, the strain trace gradient $(23)$ can be written from $(24,30)$ as equal to

$\overrightarrow{\operatorname{grad}} \operatorname{tr} \varepsilon=\frac{3 \mathrm{~A}_{0} \mathrm{k}-\alpha}{\mathrm{A}_{0} \mathrm{k}} \eta \frac{\partial \mathrm{C}}{\partial \mathrm{x}}$

Similarly, the Laplacian of the strain trace will be given by,

$\Delta \operatorname{tr} \varepsilon=\operatorname{div}(\overrightarrow{\operatorname{grad}} \operatorname{tr} \varepsilon)=\operatorname{div}\left(\frac{3 \mathrm{~A}_{0} \mathrm{k}-\alpha}{\mathrm{A}_{0} \mathrm{k}} \eta \frac{\partial \mathrm{C}}{\partial \mathrm{x}}\right)=\frac{3 \mathrm{~A}_{0} \mathrm{k}-\alpha}{\mathrm{A}_{0} \mathrm{k}} \eta \Delta \mathrm{C}$

Introducing the relations (31) and (32) into the equation (26), enables the model's fundamental constitutive equation to be obtained:

$\frac{\partial C}{\partial t}=D\left[\left(1+V_{1} \eta^{2} C+V_{2} \eta^{3} C^{2}\right) \frac{\partial^{2} C}{\partial x^{2}}+\eta^{2}\left(V_{3}+V_{4} C\right)\left(\frac{\partial C}{\partial x}\right)^{2}\right]$

Where:

$\mathrm{V}_{1}=-3 \mathrm{~A}_{0} \mathrm{kCtr} \varepsilon+2 \alpha \operatorname{tr} \varepsilon+\alpha$

$\mathrm{V}_{2}=9 \mathrm{~A}_{0} \mathrm{k}-3 \alpha$

$\mathrm{V}_{3}=\alpha-3 \mathrm{~A}_{0} \mathrm{ktr} \varepsilon+2 \alpha \operatorname{tr} \varepsilon$

$\mathrm{V}_{4}=9 \eta A_{0} \mathrm{k}+3 \eta \alpha-\frac{2 \eta \alpha^{2}}{\mathrm{~A}_{0} \mathrm{k}}$

One should notice that the relation (33) merges with the constitutive law of the model, neglecting the volume change, proposed by Derrien and Gilormini (2006) which is recovered by taking $\mathrm{V}_{1}=\mathrm{V}_{3}=\alpha$ and $\mathrm{V}_{2}=\mathrm{V}_{4}=0$.

\section{BOUNDARY CONDITION}

The boundary condition is obtained by equating the chemical potential of water in humid air, $\hat{\mu}_{\mathrm{w}}=\hat{\mu}_{0}+\mathrm{RT} \ln \frac{\mathrm{p}_{\mathrm{w}}}{\mathrm{p}_{0}}$ (where $\hat{\mu}_{0}$ is the chemical potential of water in humid air at the reference pressure $\mathrm{p}_{0}$, the partial pressure of water being $\mathrm{p}_{\mathrm{w}}$ ) with the generalized chemical potential of the polymer. The boundary condition is obviously only satisfied at the specific position $\mathrm{x}_{\mathrm{b}}$ denoting the boundary between the ambient fluid and the polymer,

Let us denote by $\mathrm{P}\left(\mathrm{x}_{\mathrm{b}}, \mathrm{t}\right)$ the pressure experienced at the boundary, and $\mathrm{C}\left(\mathrm{x}_{\mathrm{b}}, \mathrm{t}\right)$ the corresponding moisture content. The chemical potential (9) written in terms of the pressure reads,

$\tilde{\mu}_{w}(\mathrm{C})=\mu_{0}+\mathrm{RT} \ln \frac{\mathrm{C}\left(\mathrm{x}_{\mathrm{b}}, \mathrm{t}\right)}{\mathrm{C}_{0}}+\frac{3 \eta \omega_{\mathrm{w}}}{\rho_{0}}\left(\frac{\mathrm{P}\left(\mathrm{x}_{\mathrm{b}}, \mathrm{t}\right)}{\mathrm{k}}\right)\left(-\mathrm{P}\left(\mathrm{x}_{\mathrm{b}}, \mathrm{t}\right)+3 \eta \mathrm{kC}\left(\mathrm{x}_{\mathrm{b}}, \mathrm{t}\right)+\mathrm{k}\right)$

So the equality of these two chemical potentials leads to 


$$
\hat{\mu}_{0}+R T \ln \frac{\mathrm{p}_{\mathrm{w}}}{\mathrm{p}_{0}}=\mu_{0}+\mathrm{RT} \ln \frac{\mathrm{C}\left(\mathrm{x}_{\mathrm{b}}, \mathrm{t}\right)}{\mathrm{C}_{0}}+\frac{3 \eta \omega_{\mathrm{w}}}{\rho_{0}}\left(\frac{\mathrm{P}\left(\mathrm{x}_{\mathrm{b}}, \mathrm{t}\right)}{\mathrm{k}}\right)\left(-\mathrm{P}\left(\mathrm{x}_{\mathrm{b}}, \mathrm{t}\right)+3 \eta \mathrm{kC}\left(\mathrm{x}_{\mathrm{b}}, \mathrm{t}\right)+\mathrm{k}\right)
$$

Then,

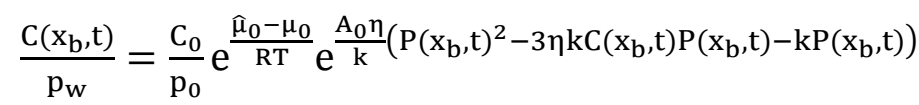

Henry's law is introduced to define sorption isotherm: the moisture at saturation is given byC $_{s}=S p_{w}$ where $S$ is the solubility of water given by $S=\frac{C_{0}}{p_{0}} e^{\frac{\hat{\mu}_{0}-\mu_{0}}{R T}}$.

Therefore,

$C\left(x_{b}, t\right)=\operatorname{Sp}_{w} e^{\frac{A_{0} \eta}{k}\left(P\left(x_{b}, t\right)^{2}-3 \eta k C\left(x_{b}, t\right) P\left(x_{b}, t\right)-k P\left(x_{b}, t\right)\right)}$

To simplify in order to solve equation (41), the following assumption is considered to be satisfied: $\left|\frac{A_{0} \eta}{k}\left(P\left(x_{b}, t\right)^{2}-3 \eta k C\left(x_{b}, t\right) P\left(x_{b}, t\right)-k P\left(x_{b}, t\right)\right)\right| \rightarrow 0$

As a result, expression (41) simplifies as follows,

$C\left(x_{b}, t\right)=\operatorname{Sp}_{w}\left(1+\frac{A_{0} \eta}{k}\left(P\left(x_{b}, t\right)^{2}-3 \eta k C\left(x_{b}, t\right) P\left(x_{b}, t\right)-k P\left(x_{b}, t\right)\right)\right)$

Through (42), we then get,

$C\left(x_{b}, t\right)=S p_{w} \frac{1+\frac{A_{0} \eta}{k}\left(P\left(x_{b}, t\right)^{2}-k P\left(x_{b}, t\right)\right)}{1+3 \eta^{2} A_{0} P\left(x_{b}, t\right) S p_{w}}$

The total pressure at the boundary position $\mathrm{x}_{\mathrm{b}}$ is given by,

$P\left(x_{b}, t\right)=P i s+P e x=\frac{\alpha}{A_{0}} \eta\left[C\left(x_{b}, t\right)-\overline{C(t)}\right]+P e x$

Then,

$\mathrm{C}\left(\mathrm{x}_{\mathrm{b}}, \mathrm{t}\right)=\overline{\mathrm{C}(\mathrm{t})}+\frac{\mathrm{P}\left(\mathrm{x}_{\mathrm{b}}, \mathrm{t}\right)-\mathrm{Pex}}{\overline{\frac{\alpha}{\mathrm{A}_{0}} \eta}}$

Substituting for (45) in (43) yields:

$\frac{P\left(x_{b}, t\right)-P e x}{\frac{\alpha}{A_{0}} \eta}+\overline{C(t)}=S_{w} \frac{1+\frac{A_{0} \eta}{k}\left(P\left(x_{b}, t\right)^{2}-k P\left(x_{b}, t\right)\right)}{1+3 \eta^{2} A_{0} P\left(x_{b}, t\right) S p_{w}}$

The relation (46) above leads to the following equation as a function of the variable $P\left(x_{b}, t\right)$ :

$a_{1} P\left(x_{b}, t\right)^{2}+a_{2} P\left(x_{b}, t\right)+a_{3}=0$ 
Where

$\mathrm{a}_{1}=\operatorname{Sp}_{\mathrm{e}} \eta^{2}\left(3 \mathrm{~A}_{0}-\frac{\alpha}{\mathrm{k}}\right)$

$\mathrm{a}_{2}=1-\left(3 \eta^{2} \mathrm{~A}_{0} \mathrm{Pex}-3 \alpha \eta^{3} \overline{\mathrm{C}(\mathrm{t})}-\alpha \eta^{2}\right) S \mathrm{p}_{\mathrm{w}}$

$\mathrm{a}_{3}=\frac{\alpha}{\mathrm{A}_{0}} \eta\left(\overline{\mathrm{C}(\mathrm{t})}-\mathrm{Sp}_{\mathrm{w}}\right)-\operatorname{Pex}$

The single solution of equation (47) having a physical meaning is

$P\left(x_{b}, t\right)=\frac{-a_{2}+\sqrt{a_{2}^{2}-4 a_{1} a_{3}}}{2 a_{1}}$

In expression (51), by replacing $\mathrm{P}\left(\mathrm{x}_{\mathrm{b}}, \mathrm{t}\right)$ with the form (44), we obtain,

$C\left(x_{b}, t\right)=\frac{1}{\frac{\alpha}{A_{0}} \eta}\left(\frac{-a_{2}+\sqrt{a_{2}^{2}-4 a_{1} a_{3}}}{2 a_{1}}-P e x\right)+\overline{C(t)}=\frac{1}{\frac{\alpha}{A_{0}} \eta}\left(\frac{-a_{2}+a_{2} \sqrt{1-4 \frac{a_{1} a_{3}}{a_{2}^{2}}}}{2 a_{1}}-P e x\right)+\overline{C(t)}$

In the case of the amount $\frac{a_{1} a_{3}}{a_{2}^{2}} \rightarrow 0$ the following approximation is considered to be satisfied

$\sqrt{1-4 \frac{a_{1} a_{3}}{a_{2}^{2}}}=1-2 \frac{a_{1} a_{3}}{a_{2}^{2}}$

As a consequence, expression (52) reduces to:

$C\left(x_{b}, t\right)=\overline{C(t)}-\frac{A_{0}}{\alpha \eta}\left(\frac{a_{3}}{a_{2}}+P e x\right)$

Finally the boundary condition, in the case of a symmetrical hygro-mechanical loading, can be written as:

$\mathrm{C}\left(\mathrm{x}_{\mathrm{b}}, \mathrm{t}\right)=\mathrm{Sp}_{\mathrm{w}} \frac{1+\left(\frac{\mathrm{A}_{0}}{\alpha} \eta \mathrm{Pex}-\eta^{2} \overline{\mathrm{C}(\mathrm{t})}\right)\left(3 \mathrm{~A}_{0} \mathrm{Pex}-3 \alpha \eta \overline{\mathrm{C}(\mathrm{t})}-\alpha\right)}{1-\left(3 \mathrm{~A}_{0} \mathrm{Pex}-3 \alpha \eta \overline{\mathrm{C}(\mathrm{t})}-\alpha\right) \eta^{2} \mathrm{Sp}_{\mathrm{w}}}$

\section{NUMERICAL RESULTS}

The numerical simulations correspond to a $4 \mathrm{~mm}$ thick plate made of epoxy resin whose Young modulus is $3.65 \mathrm{GPa}$ and Poisson's ratio is 0.36 . The polymer plate is subjected to moisture diffusion while experiencing a hydrostatic pressure load.

Figure 1a shows the time-dependent evolution of the macroscopic (average) moisture content, as a function of the CME: $\eta=0 ; \eta=0.6$ or $\eta=2$, at an imposed pressure of $1 \mathrm{MPa}$. Increasing CME reduces the maximum moisture absorption capacity of the polymer as indicated by the evolution of the average moisture content in the steady state. Besides, figure 1a displays a comparison between the results predicted according to the present work and the model previously proposed by Derrien and Gilormini (2006) throughout the diffusion process. According to figure 1a, the discrepancies between the models significantly increase with the coefficient of moisture expansion. In particular, in the steady state, the maximum absorption 
capacity deduced from the boundary conditions differs depending on the considered model. Eventually, both the predicted maximum moisture absorption capacity and the apparent moisture diffusion coefficient may vary whether the volume change is accounted for or neglected, instead.

The evolution of the moisture content profiles through the thickness of the plate during the transient stage of the diffusion process is shown on figure $1 \mathrm{~b}$ for the case of a symmetrical pressure of $1 \mathrm{MPa}$ and $\eta=0.6$.

According to figure $1 \mathrm{~b}$, the moisture content at the boundary with humid air varies significantly throughout the transient regime. This means that the maximum moisture absorption capacity does not immediately reach its ultimate value. This effect comes from the dependence of the boundary condition on the mechanical strain experienced by the polymer, the magnitude of which changes considerably during the transient part of the diffusion process, due to the hygroscopic swelling. The results obtained are consistent with those published in reference (Youssef et al., 2009).
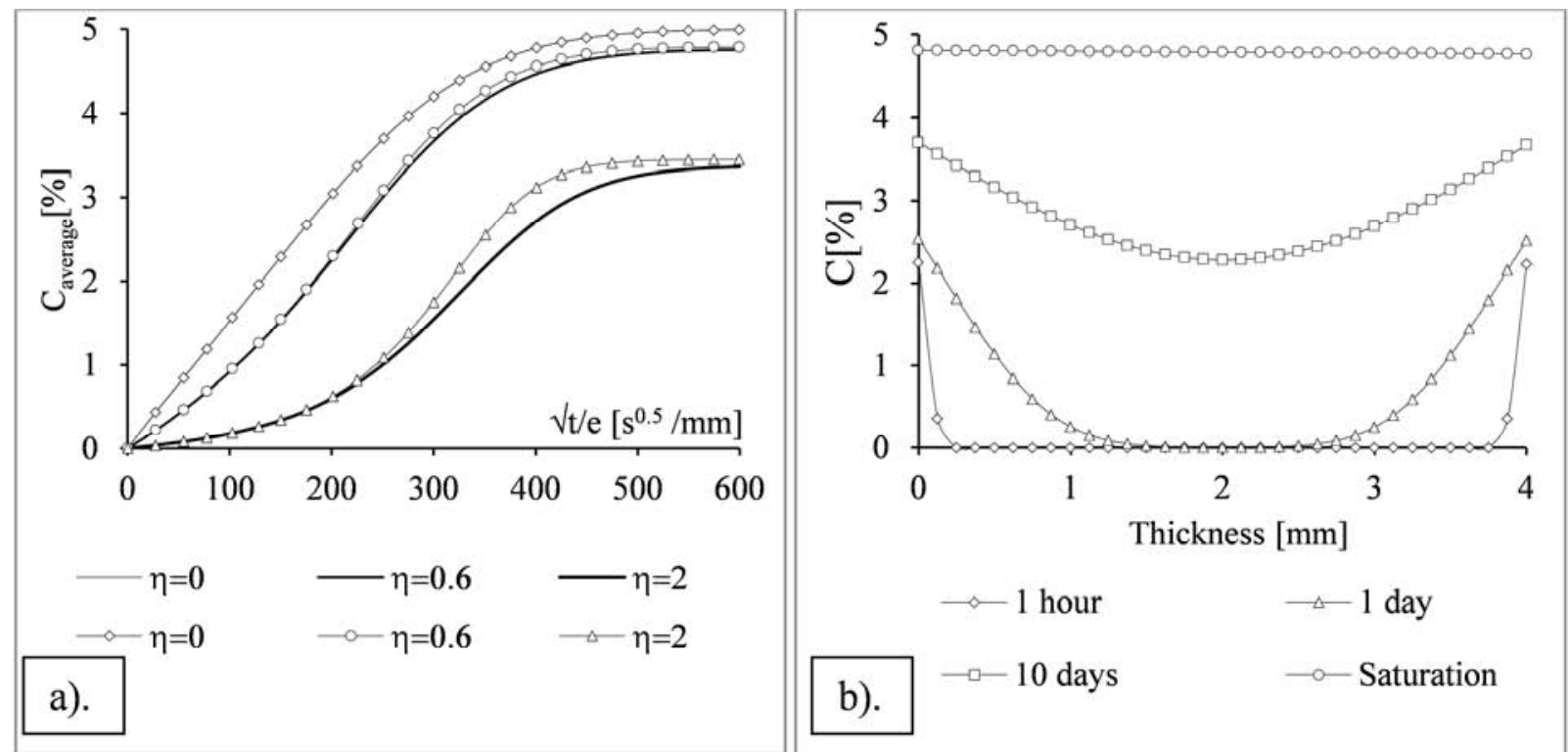

Fig. 1: a). Effect of CME on the average moisture content.The continuous lines (without marks) show the results predicted by Derrien and Gilormini (2006) model, whereas the continuous lines with marks correspond to the model developed in the present work.b). In-depth time-dependent moisture content profiles.

Figure 2 shows the effect induced by the application of an external pressure, varying from $1 \mathrm{MPa}$ to $20 \mathrm{MPa}$, on the time-dependent moisture content. The Coefficients of Moisture Expansion used in order to obtain the results depicted on figures $2 \mathrm{a}$ and $2 \mathrm{~b}$ are respectively equal to 0.6 and 2. According to figure $2 \mathrm{a}$, an increased applied pressure significantly reduces the diffusion of moisture at the boundary. Figure $2 b$ shows that this effect increases with the CME. 

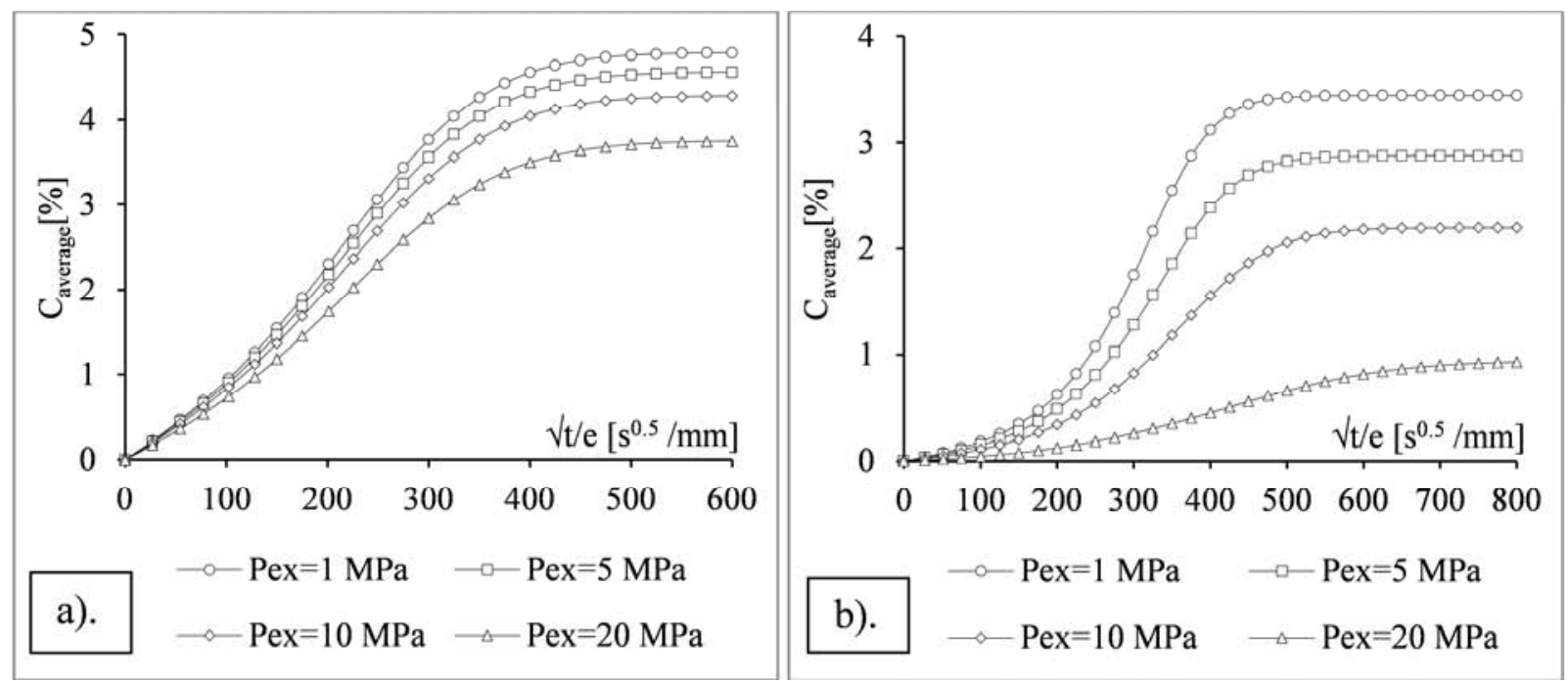

Fig.2: Effect of applied pressure on the average moisture content $a$ ). $\eta=0.6, b) . \eta=2$.

Figure 3 shows that the maximum moisture absorption capacity reached in the steady state depends almost linearly on the applied pressure. The results are consistent with (Cai and Weitsman, 1994).

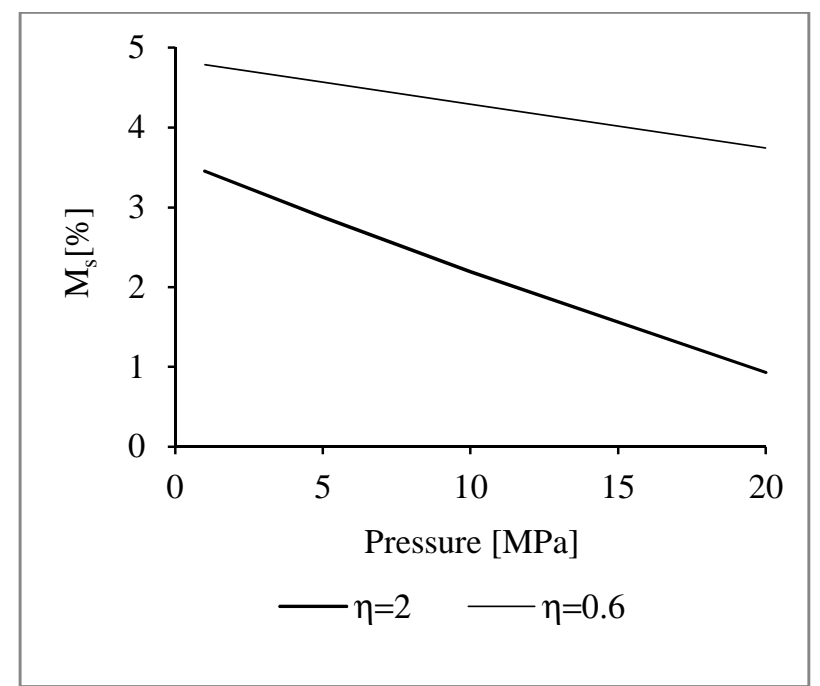

Fig. 3: Maximum steady state moisture absorption capacity, as a function of the applied external load.

\section{CONCLUSION}

The aim of the present work is to establish a model enabling the moisture diffusion within polymers under external load (symmetric moisture and pressure conditions) to be predicted. The moisture sorption results from coupled hygro-mechanical phenomena. The model developed here is the first enriched one, following many previous studies based on empirical approaches such as a the free-volume theory (Neumann and Marom, 1986; Youssef et al., 2009; Youssef et al., 2011).In contrast with previous work based on the thermodynamical approach, such as (Derrien and Gilormini, 2009), the present model accounts for the dependence of the polymer density on the mechanical states, which was previously neglected. The simulations reproduce the expected evolutions, as a function of the applied external pressure, of the maximum moisture 
absorption capacity. These results are compatible with results from published experimental investigations (Wan et al., 2005).

In future works, realistic evolutions of the hygro-mechanical properties (i.e. the elastic moduli and coefficient of moisture expansion), occurring during the diffusion process, will be taken into account. Besides, sorption-desorption case showing a hysteresis effect is an interesting feature occurring in practice in epoxy resin and its composites (Henson and Weitsman, 1986). This field of research is under investigation by the authors: ongoing experimental studies should provide results to be compared with the numerical predictions. Finally, the model presented in this communication will be extended to the case of polymer matrix composites.

\section{REFERENCES}

Aboudi, J., Williams, T.O., 2000. A coupled mico-macromechanical analysis of hygrothermoelastic composites. International Journal of Solids and Structures, 37, 41494179.

Cai, L.-W., Weistman, Y., 1994. Non-Fickian Moisture Diffusion in Polymeric Composite. Journal of composite materials, 28, 130-154.

Derrien K., Gilormini, P. Interaction between stress and diffusion in polymers, Defect and Diffusion Forum, 258-260, 447-452, 2006.

Derrien, K., Gilormini, P., 2009. The effect of moisture-induced swelling on the absorption capacity of transversely isotropic elastic polymer-matrix composites. International Journal of Solids and Structures, 46, 1547-1553.

Fréour, S., Jacquemin, F., Guillén, R., (2005). On an analytical self-consistent model for internal stress prediction in fiber-reinforced composites submitted to hygroelastic load. Journal of Reinforced Plastics and Composites, 24, 1365-1377.

Gilat, O., Broutman, L.J., 1978. Effect of External Stress on Moisture Diffusion and Degradation in a Graphite Reinforced Epoxy Laminate. ASTM STP, 658, 61-83.

Henson, M.C., Weitsman, Y., 1986. Stress effects on moisture transport in an epoxy resin and its composites", in "Composites '86: Recent Advances in Japan and the United States", edited by K. Kawaba et al., pp. 775-783.

Jacquemin, F., Vautrin, A., 2002.A closed-form solution for the internal stresses in thick composite cylinders induced by cyclical environmental conditions. Composite Structures, 58, 1-9.

Jedidi, J., Jacquemin, F., Vautrin, A., 2005. Design of Accelerated Hygrothermal Cycles on Polymer Matrix Composites in the Case of a Supersonic Aircraft. Composite Structures, 68, 429-437.

Larché, F.C., Cahn, J.W., 1982. The effect of self-stress on diffusion in solid . ActaMetallurgica, 30, $1835-1845$.

Marom, G., Broutman, L. J. , 1981. Moisture Penetration into Composites under External Stress. Polymer Composites, 2, 132-136.

Neumann, S., Marom, G., 1986. Free-volume dependent moisture diffusion under stress in composite materials. Journal of Materials Science, 21, 26-30.

Neumann, S., Marom, G., 1987. Prediction of Moisture Diffusion Parameters in Composite Materials Under Stress. Journal of Composite Materials,21, 68-80.

Patel, B.P., Ganapathi, M., Makhecha, D.P., 2002. Hygrothermal Effects on the Structural behaviour of Thick Composite Laminates using Higher-Order Theory. Composite Structures, 56, 25-34.

Perreux, D., Suri,C., 1997. A study of the coupling between the phenomena of water absorption and damage in glass/epoxy composite pipes. Composites Science and Technology, 57, 1403-1413. 
Wan, Y.Z., Wang, Y.L., Huang, Y., He, B.M., Han, K.Y., 2005. Hygrothermal aging behaviour of VARTMed three-dimensional braided carbon-epoxy composites under external stresses.Composites Part A, 36, 1102-1109.

Weitsman, Y.J., 1990. Moisture in Composites: Sorption and Damage, in: Fatigue of Composite Materials. Elsevier Science Publisher, K.L. Reifsnider (editor), 385-429.

Weitsman, Y.J., Elahi, M., 2000. Effects of Fluids on the Deformation, Strength and Durability of Polymeric Composites - An Overview. Mechanics of Time-Dependent Materials, 4, 107-126.

Youssef, G., Fréour, S., Jacquemin, F., 2009. Stress-dependent moisture diffusion in composite materials.Journal of Composite Materials, 43, 1621-1637.

Youssef, G., Jacquemin, F., Fréour, S., 2011. Radial Pressure and thickness effects on the moisture diffusion in hollow composite cylinders. Polymer Composites, 32(6), 960-966. 